\title{
Design of Microstip Patch Antennas at UWB for Wireless Applications
}

\author{
${ }^{1}$ K. Madhu Sudhana Rao and ${ }^{2}$ M.V.S. Prasad \\ ${ }^{1}$ Department of ECE, ANU College of Engineering and Technology, Guntur, \\ Andhra Pradesh (AP), India \\ ${ }^{2}$ Department of ECE, RVR and JC College of Engineering, Chowdavaram, Guntur, \\ Andhra Pradesh (AP), India
}

\begin{abstract}
Design and analysis of microstrip patch antennas are done at ultra-wide band (3.1-10.6) which is suitable for wireless applications such as communications, radar, military applications and for commercial applications. The radiating patch may be square, circle and hexagonal and these microstrip patch antennas are done by using An-soft HFSS V13. The sub-strate material used for designing of these microstrip patch antennas is FR4 epoxy with a thickness of 1.6 and a dielectric constant of 4.4 .
\end{abstract}

Key words: Microstrip patch antenna, An-soft HFSSV13, UWB and wireless applications, radiating patch, FR4, design

\section{INTRODUCTION}

Day by day the technology keeps on improving and at the same time the people who are utilising this technology are also increasing but the bandwidth which is available will remain constant. For this reason, we are utilising this ultra-wide band which is of a frequency of 3.1-10.6. Narrow band is not used because of their disadvantages such as fading due to multipath, insecure and is of having the range resolution which is very poor. As the federal communication commission has provided the UWB as unlicensed use in 2002, later on, it is approved by FCC that UWB can be used for commercial purpose (Chandel et al., 2018; Wu et al., 2013). Microstrip patch antenna consists of a dielectric substrate which is in between the ground and the patch. Circular patch antenna is a kind of microstrip patch antenna. All these types of an antennas are called as microstrip patch antennas the variation is only that the radiating patch may be square, circle, rectangle and hexagonal. The advantage of using these microstrip patch antennas are cost will be low, weight is very less and the fabrication can be done very easily. Applications for these types of antennas are these can be used in communications, radars, military applications and commercial applications. The main advantage UWB is that it can be used instead of Bluetooth for wireless personal area networks (Li et al., 2013; Zhang et al., 2012).

\section{MATERIALS AND METHODS}

Design topolgy: The deign of microstrip patch antenna, circular patch antenna and hexagonal patch antennas are done with the help of An-soft high frequency structure simulator. The length and width of the patch are calculated by using the formulae shown as (Balanis, 2005; Pozar, 1992):

$$
\mathrm{W}=\frac{\frac{\mathrm{V}_{0}}{2 \mathrm{~F}_{\mathrm{r}} \sqrt{2}}}{\varepsilon_{\mathrm{r}}+1}
$$

where, $V_{0}=$ Velocity of light in free space:

$$
\begin{aligned}
& \mathrm{L}=\frac{\mathrm{C}}{2 \mathrm{~F}_{\mathrm{r}} \sqrt{\varepsilon_{\text {reff }}}}-2 \Delta \mathrm{l} \\
& \Delta \mathrm{l}=0.412 \mathrm{~h} \frac{\left(\varepsilon_{\text {reff }}+0.03\right)(\mathrm{w}+0.26 \mathrm{~h})}{\left(\varepsilon_{\text {reff }}-0.258\right)(\mathrm{w}+0.8 \mathrm{~h})}
\end{aligned}
$$

where, $\Delta 1=$ extension in length due to fringing effects. The effective dielectric constant is given by:

$$
\varepsilon_{\mathrm{reff}}=\frac{\varepsilon_{\mathrm{r}}+1}{2}+\frac{\varepsilon_{\mathrm{r}}-1}{2}\left[1+\left[\frac{12 \mathrm{~h}}{\mathrm{w}}\right]\right]^{-\frac{1}{2}}
$$

The actual length and width of the ground plane can be calculated by using the formulae shown as:

$$
\mathrm{L}_{\mathrm{g}}=6 \mathrm{~h}+\mathrm{L}
$$

Where:

$\mathrm{L}=$ Length of the patch

$\mathrm{h}=$ Thickness of the substrate

$$
\mathrm{W}_{\mathrm{g}}=6 \mathrm{~h}+\mathrm{W}
$$

Corresponding Author: K. Madhu Sudhana Rao, Department of ECE, KKR and KSR Institute of Technology and Sciences, Vinjanampadu, Guntur, Andhra Pradesh (AP), India 
Where:

$\mathrm{W}=$ Width of the patch

$\mathrm{h}=$ Thickness of the substrate

Length and width of the feed line is calculated by using the formulae shown as:

$$
\mathrm{B}=\frac{60 \Pi^{2}}{\sqrt{\varepsilon_{\mathrm{r}} \mathrm{Z}_{\mathrm{c}}}}
$$

Where:

$Z_{c}=$ Characteristic impedance

$\varepsilon_{\mathrm{r}}=$ Relative permittivity of the substrate

$$
\mathrm{L}_{\mathrm{f}}=\frac{\lambda_{0}}{4 \sqrt{\varepsilon_{\text {eff }}}}
$$

Radius of the patch is calculated by using the formulae shown as:

$$
\begin{aligned}
& \mathrm{a}=\frac{\mathrm{F}}{\sqrt{1+} \frac{2 \mathrm{~h}}{\prod \varepsilon_{\mathrm{r}}\left[\operatorname{In}\left(\frac{\prod \mathrm{f}}{2 \mathrm{~h}}\right)+1.7726\right]}} \\
& \mathrm{F}=\frac{8.791 * 10^{9}}{\mathrm{f}_{\mathrm{r}} \sqrt{\varepsilon_{\mathrm{r}}}}
\end{aligned}
$$

Microstrip patch antenna: Microstrip patch antenna consists of a dielectric substrate which is in between the ground and the patch. The advantage of using these microstrip patch antennas are cost will be low, weight is very less and the fabrication can be done very easily (Imamdi et al., 2018) (Fig. 1).

The above antenna is designed by using FR4 epoxy with a dimension of $40 \times 28 \times 1$.6. The dielectric constant of the material is 4.4 and loss tangent is 0.02

Circular patch antenna: It is easy to fabricate microstrip patch antenna on a curved surface rather than that of a flat surface. Circular patch antenna is a kind of microstrip patch antenna, the only difference is that the radiating patch may be square, rectangle, circle and hexagon. The advantage of using this kind of antennas is that the cost will be low, weight will be less and the fabrication can be done very easily (Keshwala et al., 2017; Radhi et al., 2017).

Circular patch antenna is designed by using FR4 epoxy with a dimension of $26 \times 16 \times 1.6$. Dielectric constant and loss tangent were given by 4.4 and 0.02 (Fig. 2). A slot with a radius of $0.2 \mathrm{~mm}$ has been kept on the circular patch antenna to shift the resonant frequency.

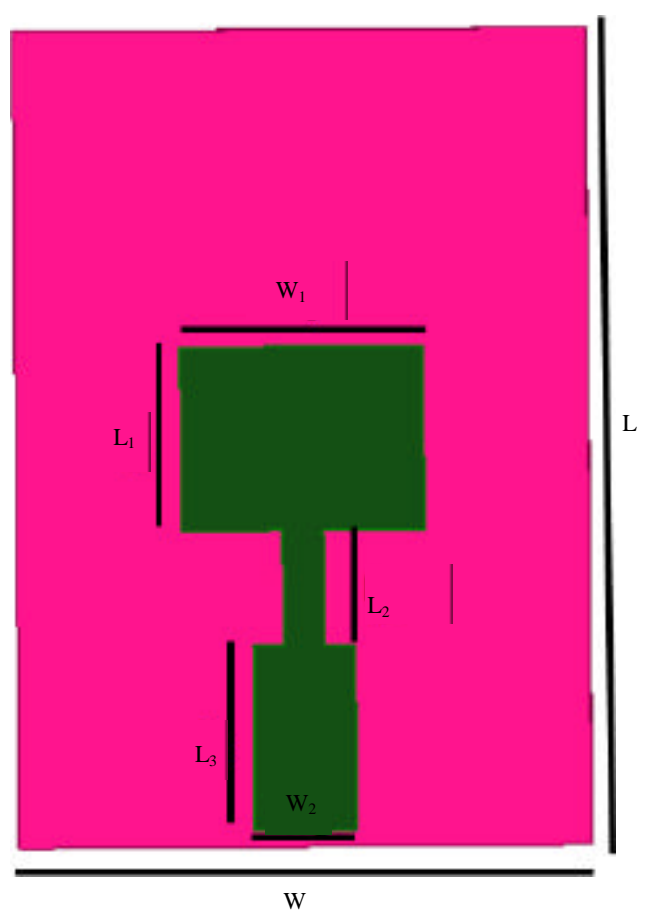

Fig. 1: Microstrip patch antenna; Dimensions are $\mathrm{L}=$ $40 \mathrm{~mm}, \mathrm{~W}=28 \mathrm{~mm}, \mathrm{~W}_{1}=9 \mathrm{~mm}, \mathrm{~L}_{1}=11.9 \mathrm{~mm}, \mathrm{~L}_{2}=$ $9.1 \mathrm{~mm}, \mathrm{~L}_{3}=10.1 \mathrm{~mm}$ and $\mathrm{W}_{2}=2 \mathrm{~mm}$

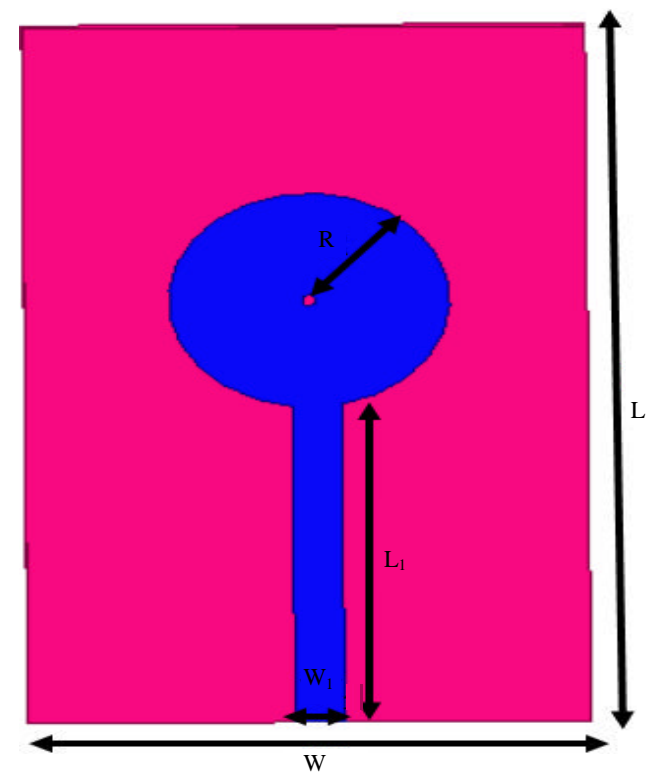

Fig. 2: Circular patch antenna; Dimensions are given by $\mathrm{L}=26 \mathrm{~mm}, \mathrm{~W}=16 \mathrm{~mm}, \mathrm{R}=4 \mathrm{~mm}, \mathrm{~L}_{1}=12 \mathrm{~mm}$ and $\mathrm{W}_{1}=1.4 \mathrm{~mm}$

Hexagonal patch antenna: Hexagonal patch antenna is a kind of microstrip patch antenna, the only difference is 
that the radiating patch may be square, circle, rectangle and hexagon. Hexagonal patch antenna is designed by using FR4 epoxy with a dimension of $60 \times 50 \times 1.6$. Dielectric constant and loss tangent were given by 4.4 and 0.02 . The advantage of using this kind of antennas is that the cost will be low, weight will be less and the fabrication can be done very easily (Fig. 3).

A slot has been kept on the hexagonal patch with a length and width of 3 and $12 \mathrm{~mm}$. This has been kept on the patch to shift its resonant frequency.

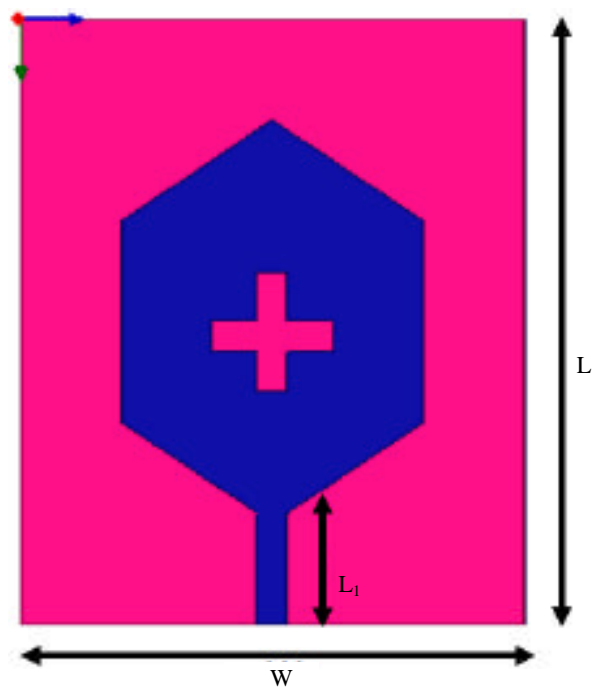

Fig. 3: Hexagonal patch antenna; Dimensions are $\mathrm{L}=$ $60 \mathrm{~mm}, \mathrm{~W}=50 \mathrm{~mm}, \mathrm{~L}_{1}=12 \mathrm{~mm}$

\section{RESULTS AND DISCUSSION}

Generally, the performance of an antenna can be shown in terms of gain, return loss, radiation pattern and VSWR. These parameters are observed and are drawn with the help of their corresponding plots.

Microstrip patch antenna: The parameters like return loss, gain, radiation pattern and VSWR for this microstrip patch antenna are shown with the help of their plots.

Return loss: Generally, an antenna is working or not is defined by one important parameter, i.e., return loss and it should be $<-10 \mathrm{~dB}$. In this case the return loss is $-14 \mathrm{~dB}$ and is obtained at a frequency of $9.8 \mathrm{GHz}$ which is in the range of UWB suitable for wireless applications (Fig. 4).

Gain: The gain of an antenna should be $>3 \mathrm{~dB}$ for any kind of an antenna. The gain obtained for microstrip patch antenna is $7.1 \mathrm{~dB}$ (Fig. 5).

Radiation pattern: The radiation pattern obtained, here is the far field radiation pattern and is expressed in terms of azimuthal angle and elevation angle (Fig. 6).

VSWR: VSWR means voltage standing wave ratio by considering the general case the voltage standing wave ratio should be $<2$. The corresponding plot for VSWR is as shown in Fig. 7.

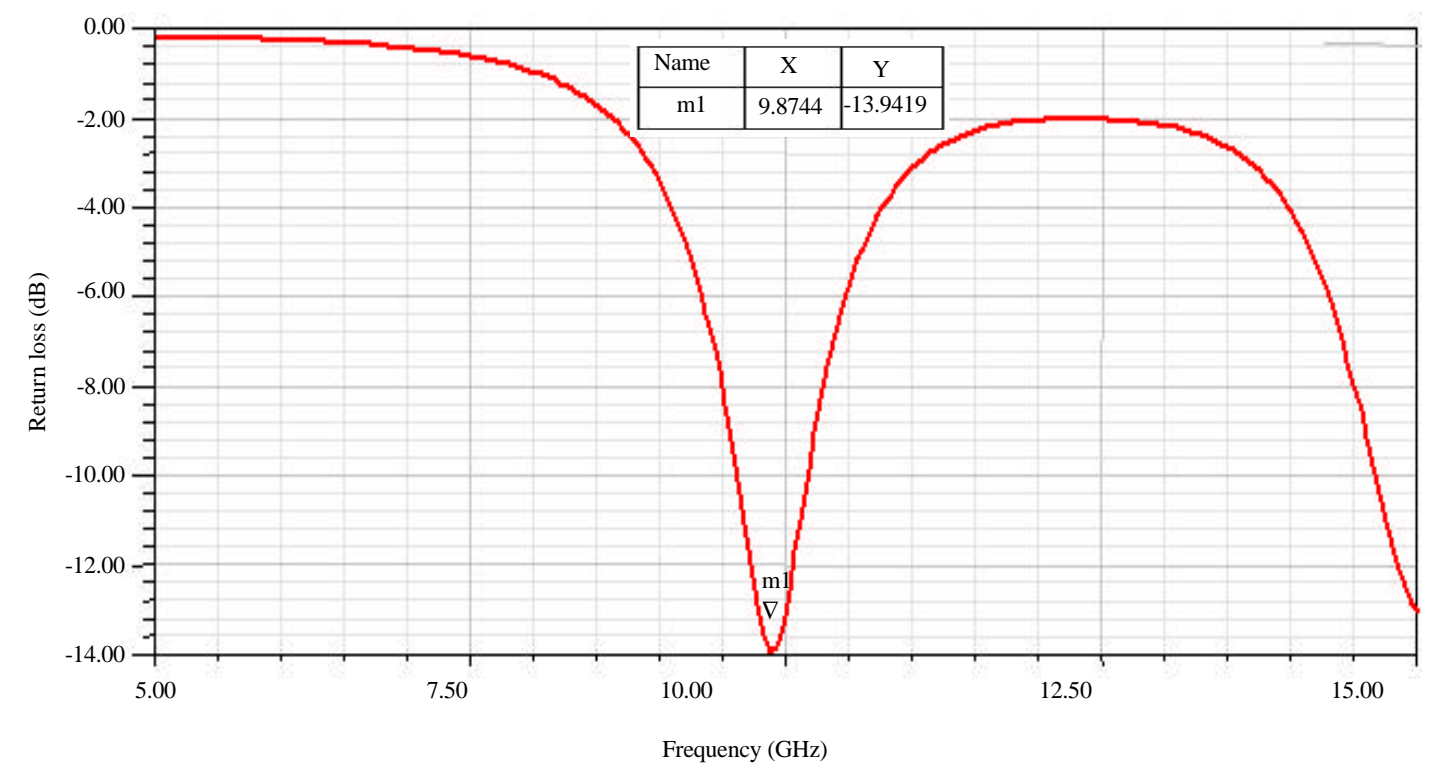

Fig. 4: Return loss curve for microstrip patch antenna; Curve Info; dB(St(1, 1)); Setup 1: Sweep 1 

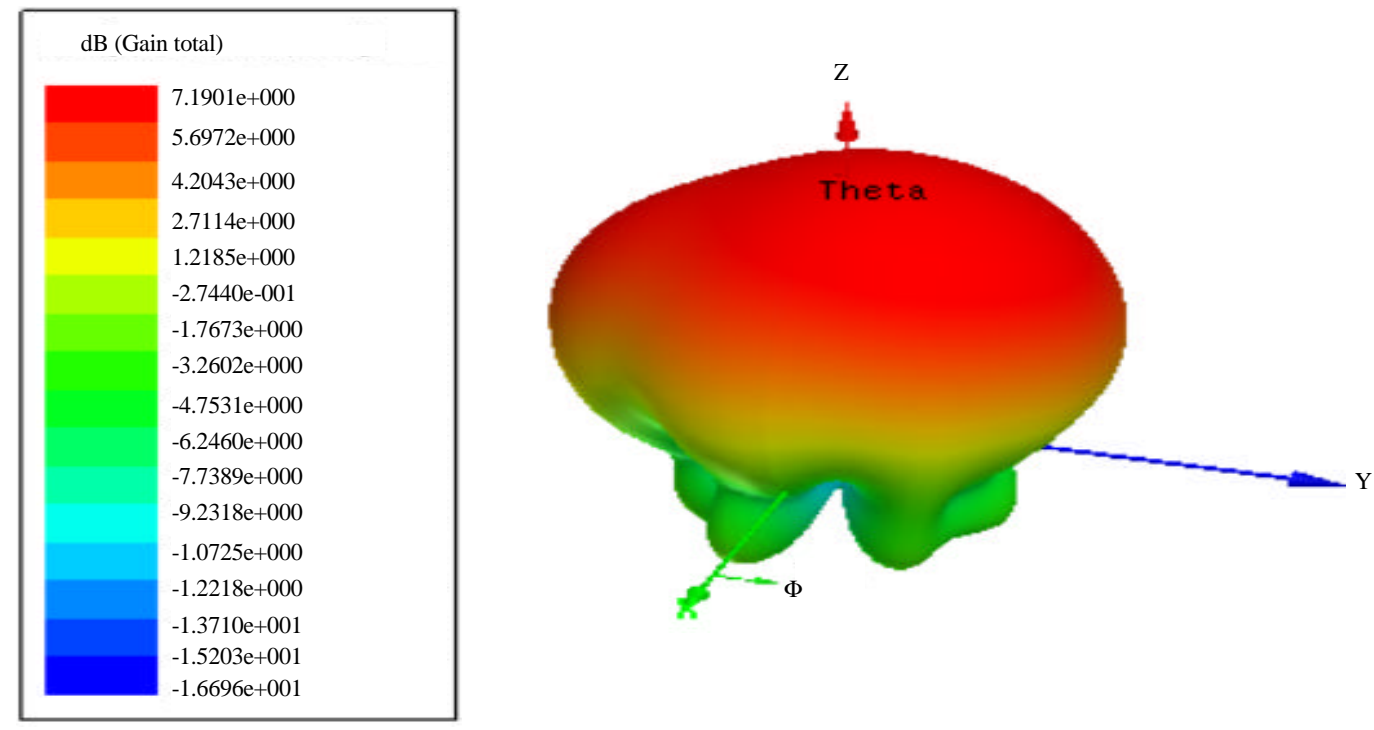

Fig. 5: Gain plot for microstrip patch antenna

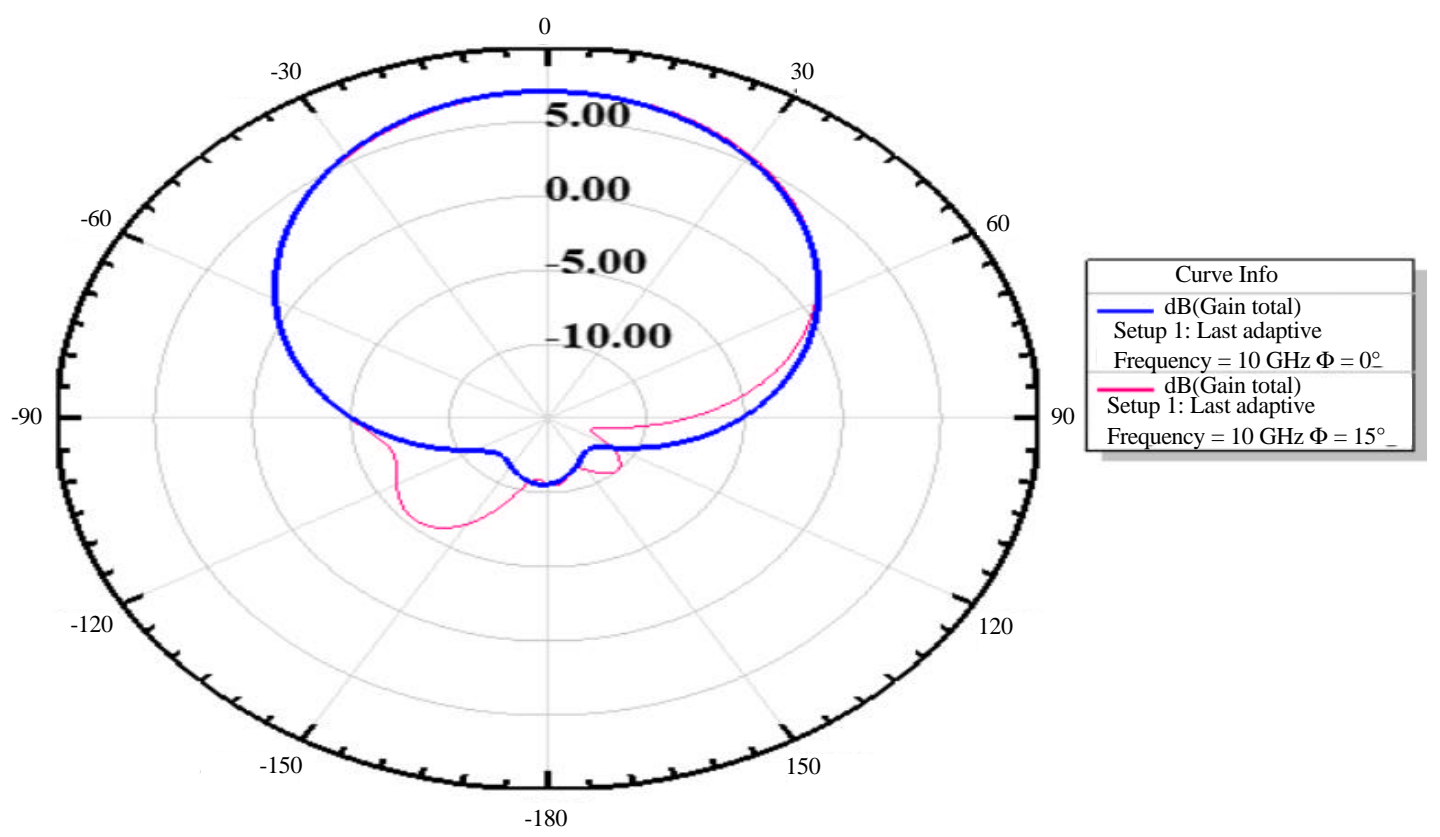

Fig. 6: Radiation plot for microstrip patch antenna

From Fig. 7, it is observed that the VSWR for microstrip patch antenna is 1.088 at a frequency of $9.8 \mathrm{GHz}$.

Circular patch antenna: The parameters like return loss, gain, radiation pattern and VSWR for this circular patch antenna are shown with the help of their plots.

Return loss: Generally, an antenna is working or not is defined by one important parameter, i.e., return loss and it should be $<-10 \mathrm{~dB}$. In this case the return loss is $-17 \mathrm{~dB}$ and is obtained at a frequency of $9.3 \mathrm{GHz}$ which is in the range of UWB suitable for wireless applications (Fig. 8).

Gain: The gain of an antenna should be $>3 \mathrm{~dB}$ for any kind of an antenna. The gain obtained for circular patch antenna is $5.795 \mathrm{~dB}$ (Fig. 9).

Radiation pattern: The radiation pattern obtained, here is the far field radiation pattern and is expressed in terms of azimuthal angle and elevation angle (Fig. 10). 


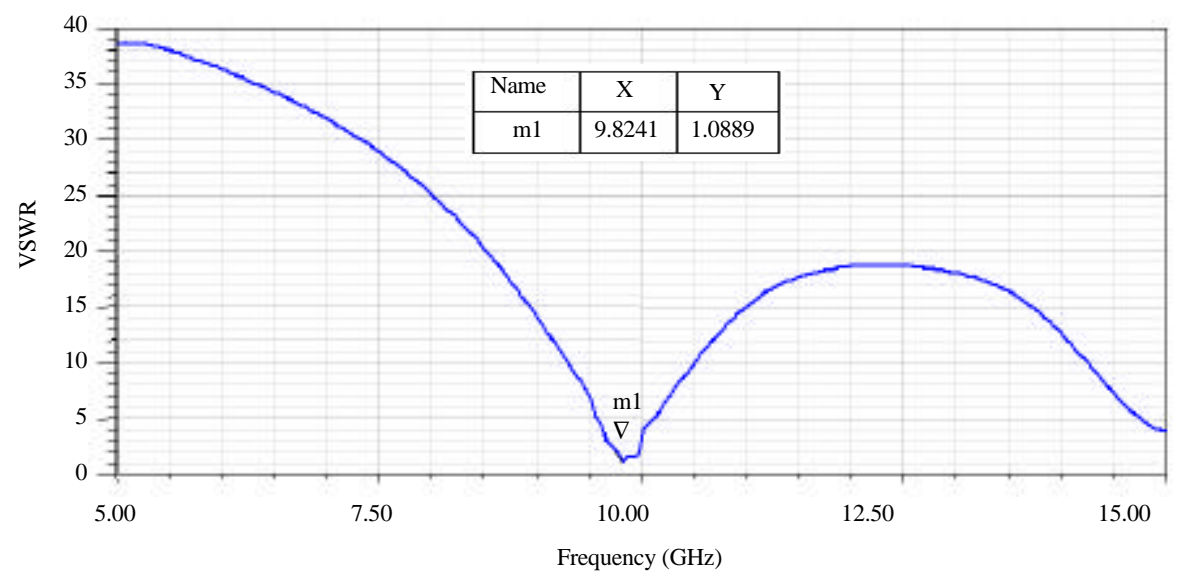

Fig. 7: VSWR plot for microstrip patch antenna

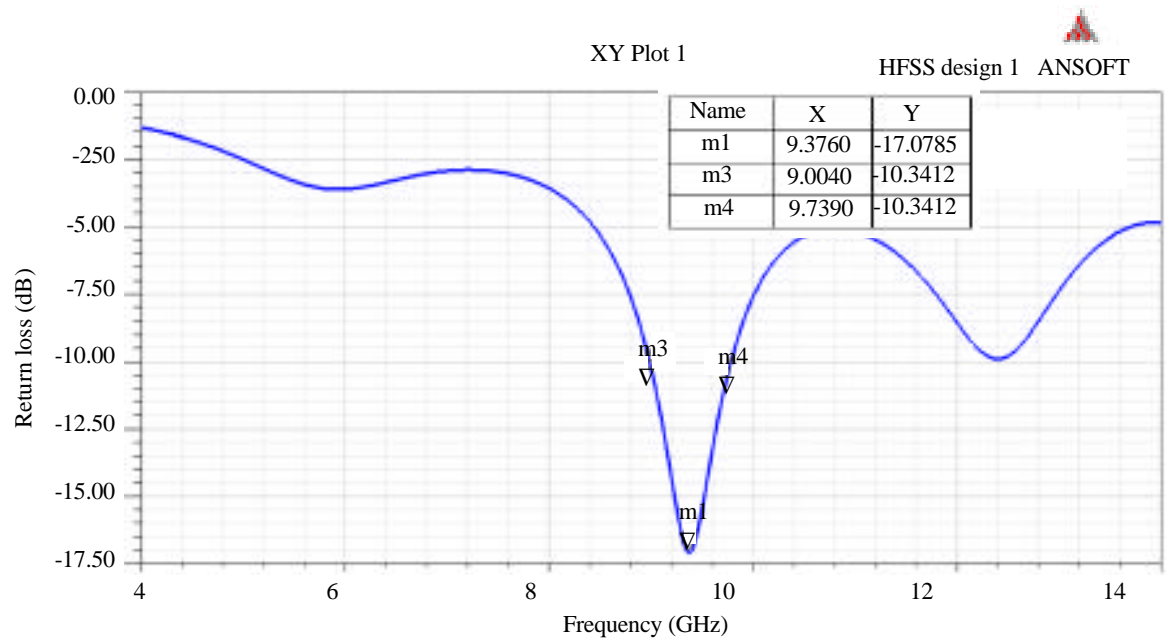

Fig. 8: Return loss curve for circular patch antenna; Curve Info; $\mathrm{dB}(\mathrm{S}(1,1))$; Setup 1: Sweep
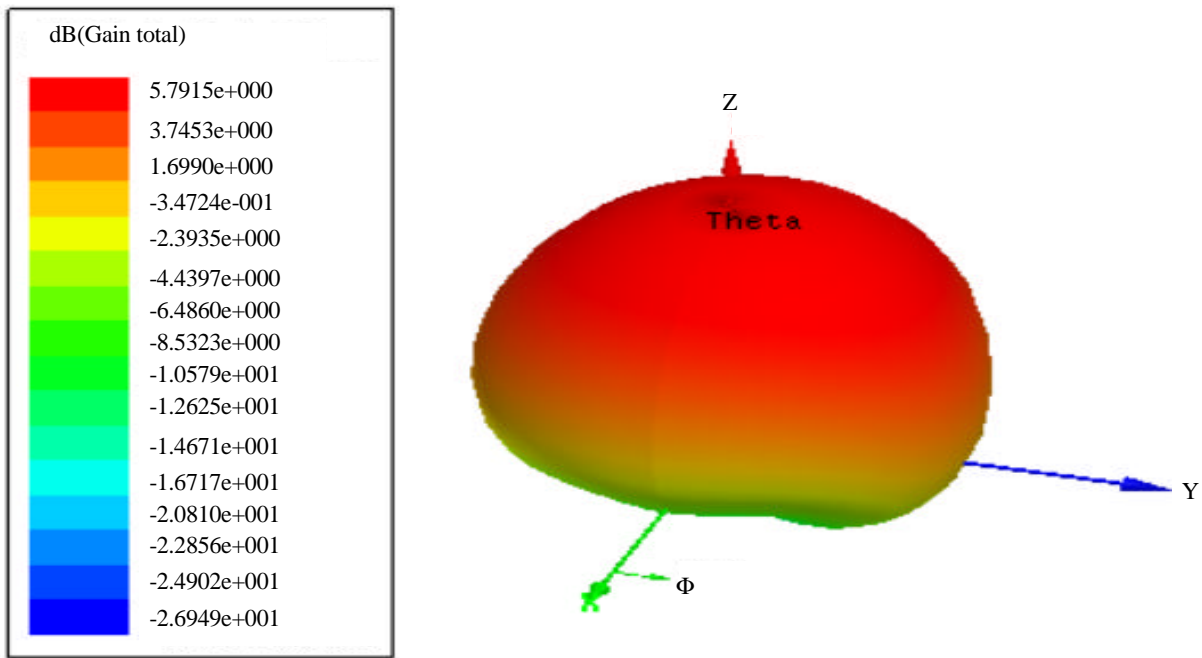

Fig. 9: Gain for circular patch antenna 


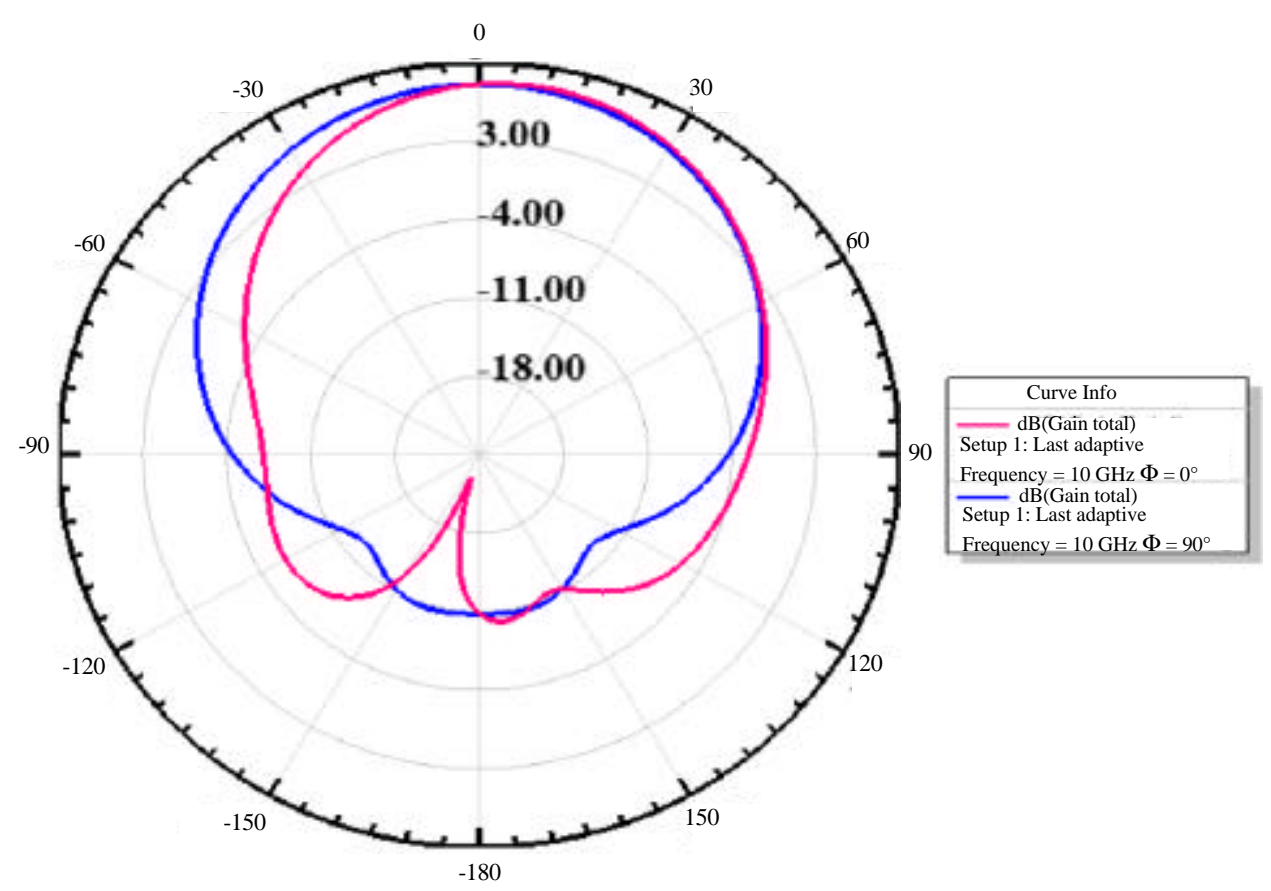

Fig. 10: Radiation pattern for circular patch antenna

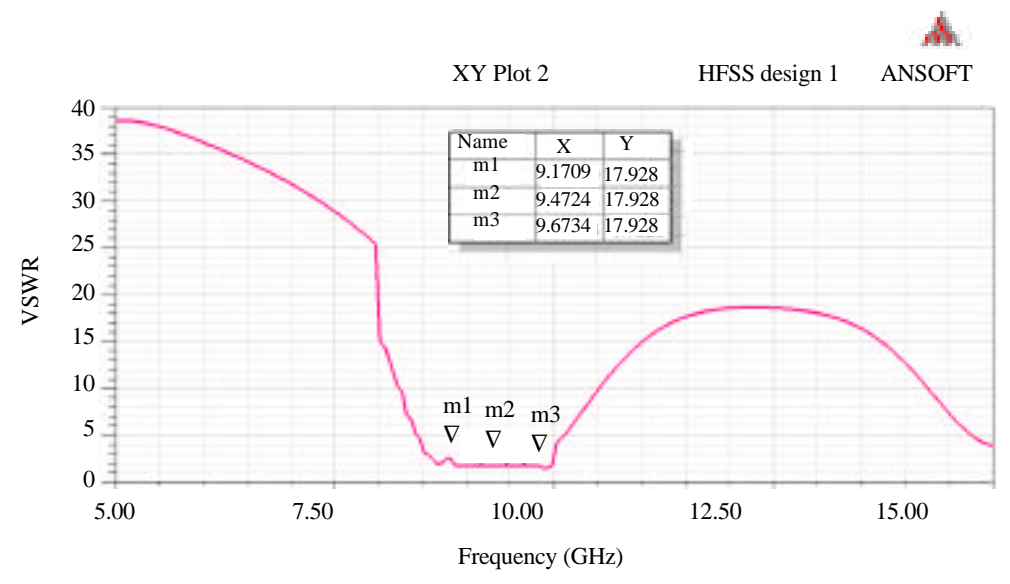

Fig. 11: VSWR plot for circular patch antenna

VSWR: VSWR means voltage standing wave ratio by considering the general case the voltage standing wave ratio should be $<2$. The corresponding plot for VSWR is as shown in Fig. 11.

From Fig. 11, it is observed that the VSWR for circular patch antenna is 1.798 at a frequency of $9.3 \mathrm{GHz}$.

Hexagonal patch antenna: The parameters like return loss, gain, radiation pattern and VSWR for this hexagonal patch antenna are shown with the help of their plots.

Return loss: Generally, an antenna is working or not is defined by one important parameter, i.e., return loss and it should be $<-10 \mathrm{~dB}$. In this case the return loss is $-22 \mathrm{~dB}$ and is obtained at a frequency of $9.8 \mathrm{GHz}$ which is in the range of UWB suitable for wireless applications (Fig. 12).

Gain: The gain of an antenna should be $>3 \mathrm{~dB}$ for any kind of an antenna. The gain obtained for hexagonal patch antenna is $6.3612 \mathrm{~dB}$ (Fig. 13).

Radiation pattern: The radiation pattern obtained, here is the far field radiation pattern and is expressed in terms of azimuthal angle and elevation angle (Fig. 14). 


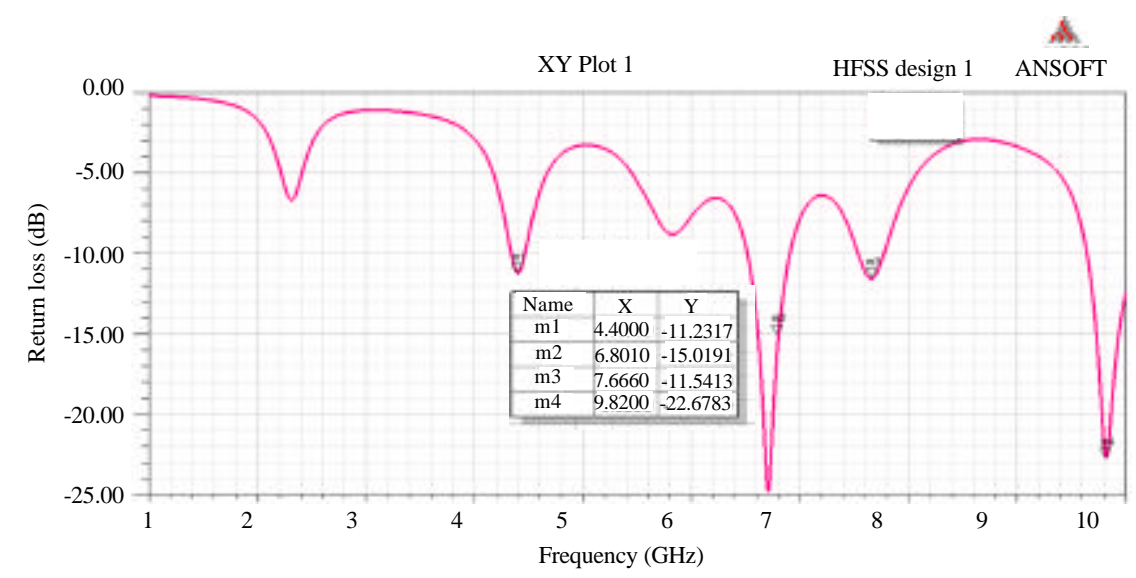

Fig. 12: Return loss plot for hexagonal patch antenna; Curve Info; $\mathrm{dB}(\mathrm{S}(1,1))$; Setup 1: Sweep

\begin{tabular}{|c|}
\hline $\mathrm{dB}$ (Gain total) \\
$6.3612 \mathrm{e}+000$ \\
$4.5796 \mathrm{e}+000$ \\
$2.7980 \mathrm{e}+000$ \\
$1.0164 \mathrm{e}+000$ \\
$-7.6526 \mathrm{e}-001$ \\
$-2.5469 \mathrm{e}+000$ \\
$-4.3285 \mathrm{e}+000$ \\
$-6.1101 \mathrm{e}+000$ \\
$-7.8917 \mathrm{e}+000$ \\
$-9.6734 \mathrm{e}+000$ \\
$-1.1455 \mathrm{e}+000$ \\
$-1.3237 \mathrm{e}+001$ \\
$-1.5018 \mathrm{e}+001$ \\
$-1.6800 \mathrm{e}+001$ \\
$-1.8581 \mathrm{e}+001$ \\
$-2.0363 \mathrm{e}+001$ \\
$-2.2145 \mathrm{e}+001$ \\
\hline
\end{tabular}

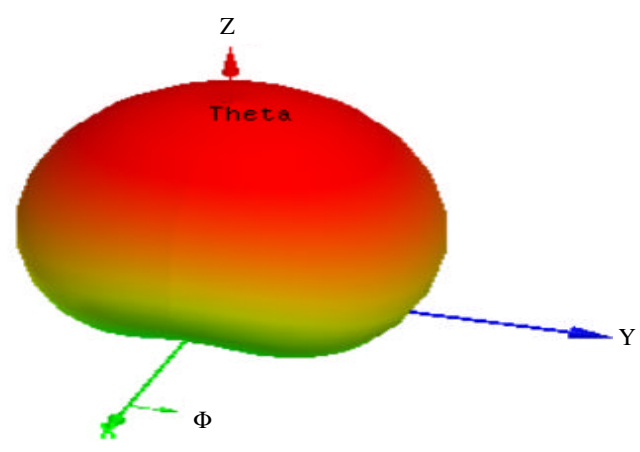

Fig. 13: Gain for hexagonal patch antenna

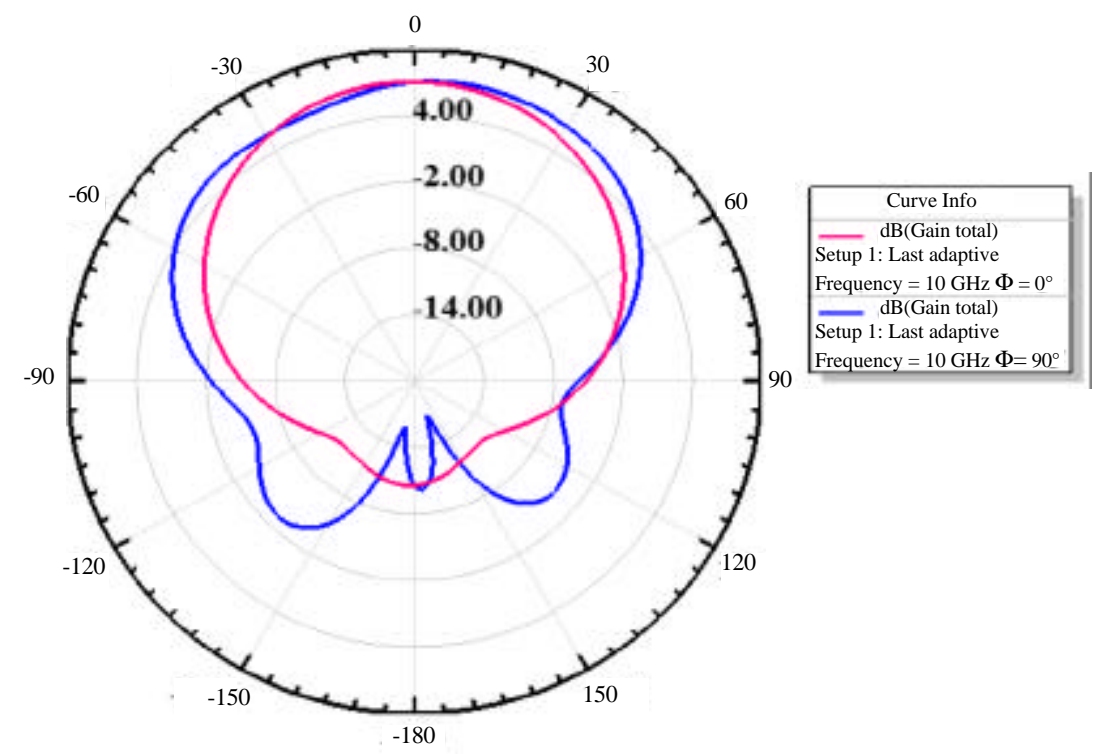

Fig. 14: Radiation pattern for hexagonal patch antenna 


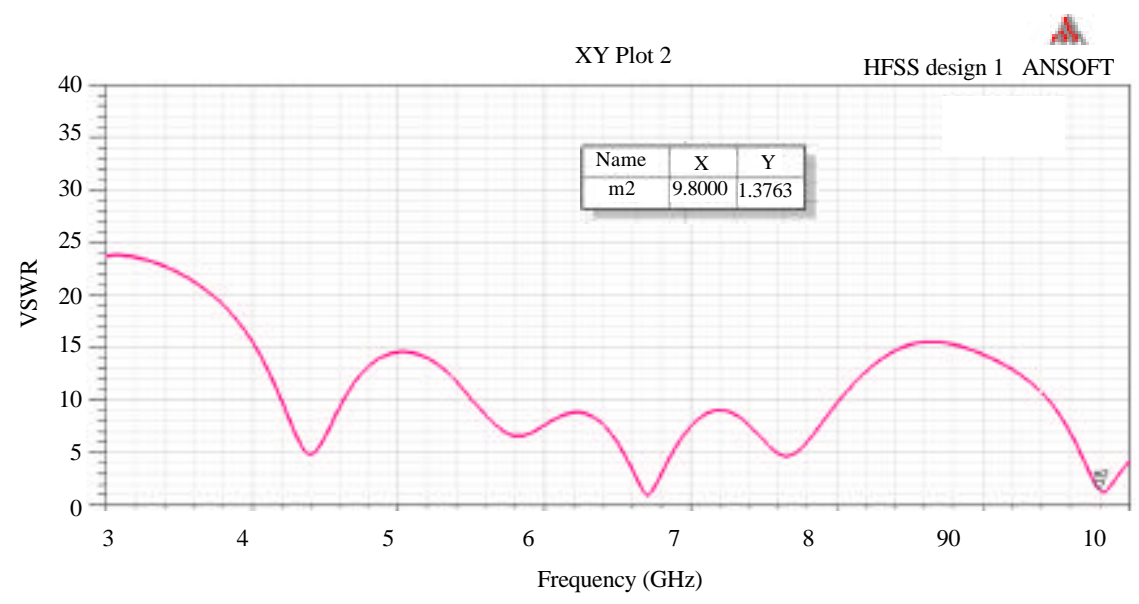

Fig. 15: VSWR plot for hexagonal patch antenna; Curve Info; dB(VSWR)(1)); Setup 1: Sweep

Table 1: Three models are compared along with their characteristics

\begin{tabular}{lcccc} 
Model types & $\begin{array}{c}\text { Frequency } \\
(\mathrm{GHz})\end{array}$ & $\begin{array}{c}\text { Return } \\
\text { loss (dB) }\end{array}$ & Gain (dB) & VSWR \\
\hline Microstrip patch antenna & 9.8 & -14 & 7.1000 & 1.088 \\
Circular patch antenna & 9.3 & -17 & 5.7950 & 1.798 \\
Hexagonal patch antenna & 9.8 & -22 & 6.3612 & 1.398 \\
\hline
\end{tabular}

VSWR: VSWR means voltage standing wave ratio by considering the general case the voltage standing wave ratio should be $<2$. The corresponding plot for VSWR is as shown in Fig. 15. From Fig. 15, it is observed that the VSWR for hexagonal patch antenna is 1.398 at a frequency of $9.8 \mathrm{GHz}$.

Comparison of all results: All these three models are compared along with their characteristics and are Table 1.

\section{CONCLUSION}

All these microstrip patch antennas are designed, simulated at UWB which is suitable for wireless applications. The performance of above antennas shows desired requirements in terms of return loss, gain and VSWR. The desired requirements of minimum return loss, positive gain and considerable VSWR are obtained within a frequency range of $3 \cdot 1-10.6 \mathrm{GHz}$ shows that it is suitable for wireless applications.

\section{RECOMMENDATION}

In future array of these antennas are to be designed and simulated for the better performance of return loss, gain, radiation pattern and VSWR.

\section{REFERENCES}

Balanis, C.A., 2005. Antenna Theory Analysis and Design. 3rd Edn., John Wiley and Sons Inc., USA.
Chandel, R., A.K. Gautam and K. Rambabu, 2018. Tapered fed compact UWB MIMO-diversity antenna with dual band-notched characteristics. IEEE. Trans. Antennas Propag., 66: 1677-1684.

Imamdi, G., M.V. Narayan, A. Navya and A. Roja, 2018. Reflector array antenna design at millimetric band for on the move applications. ARPN. J. Eng. Appl. Sci., 13: 352-359.

Keshwala, U., N. Nair and S.P. Muquit, 2017. Optimisation of circular monopole UWB antenna using the concept of golden ratio. Proceedings of the 2017 6th International Conference on Reliability, Infocom Technologies and Optimization (Trends and Future Directions) (ICRITO), September 20-22, 2017, IEEE, Noida, India, ISBN:978-1-5090-3013-2, pp: 245-247.

Li, G., H. Zhai, T. Li, X. Ma and C. Liang, 2013. Design of a compact UWB antenna Inte-Grated with GSM/WCDMA/WLAN bands. Prog. Electromagnet. Res., 136: 409-420.

Pozar, D.M., 1992. Microstrip antennas. Proc. IEEE, 80: 79-91.

Radhi, A.H., R. Nilavalan, H.S. Al-Raweshidy and N. Ab Aziz, 2017. High isolation planar UWB antennas for wireless application. Proceedings of the 2017 IEEE MTT-S International Microwave Workshop Series on Advanced Materials and Processes for $\mathrm{RF}$ and $\mathrm{THz}$ Applications (IMWS-AMP), September 20-22, 2017, IEEE, Pavia, Italy, ISBN:978-1-5386-0481-6, pp: 1-3.

Wu, Z.H., F. Wei, X.W. Shi and W.T. Li, 2013. A compact quad band-notched UWB monopole antenna loaded one lateral L-shaped slot. Prog. Electromagnet. Res., 139: 303-316.

Zhang, S.M., F.S. Zhang, W.Z. Li, T. Quan and H.Y. Wu, 2012. A compact UWB monopole antenna with WiMAX and WLAN band rejections. Prog. Electromagnet. Res. Lett., 31: 159-168. 